More than that, however, is needed in order to render the scheme a success, and one of the things of most vital importance is a comparatively full attendance of members at the annual meetings or conventions. Failure to attend three consecutive annual meetings should be considered to constitute resignation of membership, and the seat of such member should be declared vacant and filled by election from among the Associate Members.

I have not yet touched upon the financial side of the question, although that is very important. Unf rtunately, some entomologists of eminence are not very liberally paid, and have little or no private means, and yet unless the majority of members attended the annual meetings the Union would prove a failure. Most of the entomologists who would be members are, I suppose, in official positions, and we might reasonably expect that at least a portion of their expenses in attending the meetings - would be borne by the institutions with which they are connected.

Whether it would be possible to secure some sort of endowment from one of the multi-millionaires of the continent I do not know, but it might be worth attempting.

I have not in this paper made any reference to the matters with which such a Union would deal. Some of these I suggested in my two presidential addresses, and many others will readily occur to any one giving the subject the slightest thought.

The great thing is to secure co-operation among the principal workers in the science, and to eliminate all things which tend to dissension and discord. If I cculd be of any assistance in the organization of such a Union, I should be happy to do all I could.

\title{
DR. WILLIAM SAUNDERS, C. M. G.
}

His many friends in Canada and elsewhere will join with us in offering very hearty congratulations to DR. WILLIAM SAUNDERS upon the distinguished honour that he has received from our gracious Sovereign

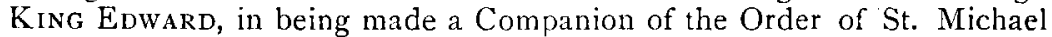
and St. George. This honour is conferred only upon those who have rendered eminent service to the Empire in some capacity or other. Few men assuredly have done more for Canada than the Director of the Experimental Farms of the Dominion in advancing and improving agriculture and fruit-growing in all their departments throughout the length and breadth of the land, and especially in the Northwest Provinces. We trust that Dr. Saunders will be preserved in health and strength for the performance of his varied and arduous labours for many a year to come. 